\title{
SISTEM PENGAMATAN KONDISI LALU LINTAS BERBASIS DATA GPS PADA SMARTPHONE (STUDI KASUS: KOTA DENPASAR)
}

\author{
Gede Herdian Setiawan*1, Ketut Dedy Suryawan ${ }^{2}$ \\ Sekolah Tinggi Manajemen Informatika dan Teknik Komputer (STMIK) STIKOM Bali \\ Email: 1'gedeherdian@stikom-bali.ac.id, 2dedymeng@stikom-bali.ac.id \\ *Penulis Korespondensi
}

(Naskah masuk: 27 Maret 2019, diterima untuk diterbitkan: 13 Mei 2019)

\begin{abstract}
Abstrak
Pertumbuhan jumlah kendaraan yang semakin meningkat setiap tahunnya mengakibatkan volume kendaraan yang melintasi ruas jalan semakin padat yang kerap mengakibatkan kemacetan lalu lintas. Kemacetan lalu lintas dapat menjadi beban biaya yang signifikan terhadap kegiatan ekonomi masyarakat. Informasi lalu lintas yang dinamis seperti informasi kondisi lalu lintas secara langsung (real time) akan membantu mempengaruhi aktivitas masyarakat pengguna lalu lintas untuk melakukan perencanaan dan penjadwalan aktivitas yang lebih baik. Penelitian ini mengusulkan model pengamatan kondisi lalu lintas berbasis data GPS pada smartphone, untuk informasi kondisi lalu lintas secara langsung. GPS Receiver pada smartphone menghasilkan data lokasi secara instan dan bersifat mobile sehingga dapat digunakan untuk pengambilan data kecepatan kendaraan secara langsung. Kecepatan kendaraan diperoleh berdasarkan jarak perpindahan koordinat kendaraan dalam satuan detik selanjutnya di konversi menjadi satuan kecepatan $(\mathrm{km} / \mathrm{jam})$ kemudian data kecepatan kendaraan di proses menjadi informasi kondisi lalu lintas. Secara menyeluruh model pengamatan berfokus pada tiga tahapan, yaitu akuisisi data kecepatan kendaraan berbasis GPS pada smartphone, pengiriman data kecepatan dan visualisasi kondisi lalu lintas berbasis GIS. Pengujian dilakukan pada ruas jalan kota Denpasar telah mampu mendapatkan data kecepatan kendaraan dan mampu menunjukkan kondisi lalu lintas secara langsung dengan empat kategori keadaan lalu lintas yaitu garis berwarna hitam menunjukkan lalu lintas macet dengan kecepatan kendaraan kurang dari $17 \mathrm{~km} / \mathrm{jam}$, merah menunjukkan padat dengan kecepatan kendaraan $17 \mathrm{~km} / \mathrm{jam}$ sampai $27 \mathrm{~km} / \mathrm{jam}$, kuning menunjukkan sedang dengan kecepatan kendaraan 26 km/jam sampai 40 km/jam dan hijau menunjukkan lancar dengan kecepatan kendaraan diatas $40 \mathrm{~km} / \mathrm{jam}$.
\end{abstract}

Kata kunci: Smartphone, GPS, Pemantauan Kondisi Lalu Lintas

\section{TRAFFIC MONITORING SYSTEM BASED GPS DATA ON THE SMARTPHONE (A CASE STUDY: DENPASAR)}

\begin{abstract}
The growth in the number of vehicles that is increasing every year has resulted in the volume of vehicles crossing the road increasingly congested which often results in traffic congestion. Traffic congestion can be a significant cost burden on economic activities. Dynamic traffic information such as information on real time traffic conditions will help influence the activities of the traffic user community to better plan and schedule activities. This study proposes a traffic condition observation model based on GPS data on smartphones, for information on real time traffic conditions. The GPS Receiver on the smartphone produces location and coordinate data instantly and is mobile so that it can be used for direct vehicle speed data retrieval. Vehicle speed is obtained based on the displacement distance of the vehicle's coordinates in units of seconds and then converted into units of speed $(\mathrm{km} / \mathrm{h})$, the vehicle speed data is then processed into information on traffic conditions. Overall, the observation model focuses on three stages, namely GPS-based vehicle speed data acquisition on smartphones, speed data delivery and visualization of GIS-based traffic conditions. Tests carried out on the Denpasar city road segment have been able to obtain vehicle speed data and are able to show traffic conditions directly with four categories of traffic conditions, namely black lines indicating traffic jammed with vehicle speeds of less than $17 \mathrm{~km} / \mathrm{h}$, red indicates heavy with speed vehicles 17 to $27 \mathrm{~km} / \mathrm{h}$, yellow indicates medium speed with vehicles $26 \mathrm{~km} / \mathrm{h}$ to $40 \mathrm{~km} / \mathrm{h}$ and green shows fluent with vehicle speeds above $40 \mathrm{~km} / \mathrm{h}$.
\end{abstract}

Keywords: Smartphone, GPS, Traffic Monitoring System 


\section{PENDAHULUAN}

Jumlah pertumbuhan populasi penduduk di kota Denpasar meningkat $2 \%$ setiap tahunnya. Pertumbuhan populasi berkontribusi dengan peningkatan jumlah alat transportasi yang akan mempengaruhi risiko meningkatnya pula masalah lalu lintas, seperti kemacetan dan kecelakaan. Untuk itu diperlukan mekanisme penanganan masalah transportasi di kota Denpasar untuk meminimalasir terjadi masalah lalu lintas (Widyantara dan Sastra, 2015).

Permasalahan lalu lintas seperti kemacetan dapat membebankan biaya yang signifikan terhadap kegiatan ekonomi dan sosial. Informasi lalu lintas yang cepat dinamis akan mempengaruhi aktivitas masyarakat pengguna lalu lintas untuk melakukan perencanaan dan penjadwalan aktivitas yang lebih baik.

Pengamatan kondisi lalu lintas dapat dilakukan dengan melakukan pengamatan secara langsung yang disebut Direct Method atau dengan melakukan pengamatan berdasarkan data-data yang direkam dengan menggunakan peralatan pemantau seperti kamera pemantau lalu lintas, sensor pemantau lalu lintas dan data spasial khusus pemantau lalu lintas seperti GPS.

GPS reciver sudah semakin berkembang dan saat ini sudah mampu terintegrasi pada telepon pintar (smartphone). Berbagai inovasi untuk pengembangan GPS smartphone sudah banyak dilakukan seperti sistem pelacakan kendaraan dengan media GPS pada smartphone yang digunakan untuk mempermudah memantau secara langsung posisi kendaraan (Mustapha, dkk., 2014). Sistem GPS pada smartphone dikembangkan untuk mendukung mobilitas survei seperti survei untuk memetakan lahan pertanahan, melalui GPS pada smartphone sangat mudah untuk mengirimkan koordinat lahan survei sehingga manjadikan data lebih akurat (Avinas, dkk., 2016). Dalam kegiatan medis GPS pada smatphone digunakan untuk sistem pencarian rute jalur te rpendek untuk mobil ambulan, sehingga mobil ambulan yang sedang membawa pasien bisa mengetahui jalur tercepat untuk mencapai rumah sakit yang dituju (Dekreneris, 2010).

Penelitian ini mengusulkan model pengamatan kondisi lalu lintas berbasis data GPS pada smartphone, untuk informasi kondisi lalu lintas secara langsung. GPS Receiver pada smartphone menghasilkan data lokasi dan koordinat secara instan dan bersifat mobile sehingga dapat digunakan untuk pengambilan data kecepatan kendaraan secara langsung. Secara menyeluruh model pengamatan berfokus pada tiga tahapan, yaitu akuisisi data kecepatan kendaraan berbasis data GPS pada smartphone, pengiriman data kecepatan dan memberikan informasi kondisi lalu lintas secara langsung.

\section{METODE PENELITIAN}

Penelitian ini mengusulkan model pengamatan kondisi lalu lintas berdasarkan data kecepatan kendaraan. Kecepatan kendaraan diperoleh melalui rumus kecepatan yaitu jarak dibagi dengan waktu tempuh (Setyawan, dkk., 2019) dalam penelitian ini nilai jarak tempuh kendaraan dibagi dengan waktu yang diperlukan untuk menempuh jarak tersebut. Kecepatan kendaraan berbasis GPS smartphone menggunakan nilai jarak tempuh dari hasil perpindahan koordinat dalam satuan detik yang kemudian dikonversi menjadi nilai kecepatan yang dinyatakan dalam satuan kecepatan $\mathrm{km} / \mathrm{jam}$. Data kecepatan kendaraan akan dijadikan acuan untuk menetukan tingkat kepadatan lalu lintas. Secara umum model pengematan kondisi lalu lintas terdiri dari tiga proses yaitu, akuisisi data kecepatan, pengiriman data kecepatan, proses informasi kondisi lalu lintas seperti ditunjukkan pada Gambar 1.

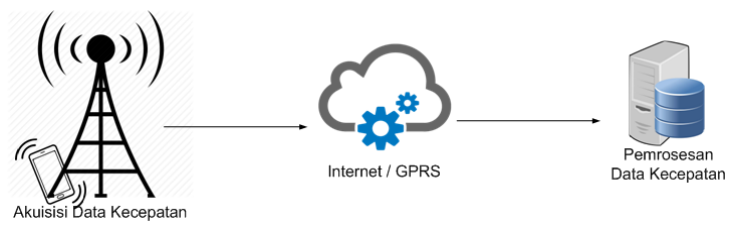

Gambar 1. Arstitektur Pengamatan Lalu Lintas

\subsection{Geofence Model}

Akuisisi data kecepatan kendaraan berbasis data GPS pada smartphone menggunakan fitur geofence. Geofence merupakan sebuah fitur terintegrasi yang memanfaatkan komponen GPS pada smartphone yang berfungsi untuk menentukan area geografis secara virtual. Geofence bekerja dengan memetakan lokasi atau area tertentu berdasarkan besaran radius yang sudah ditentukan, dengan geofence sangat mudah untuk memetakan atau menentukan area secara virtual pada peta. Manfaat geofence sangat beragam sebagai contohnya memetakan area perkantoran, area gudang, memetakan area lokasi pelanggan atau sebagai area pengawasan (Setiawan, dkk., 2016).

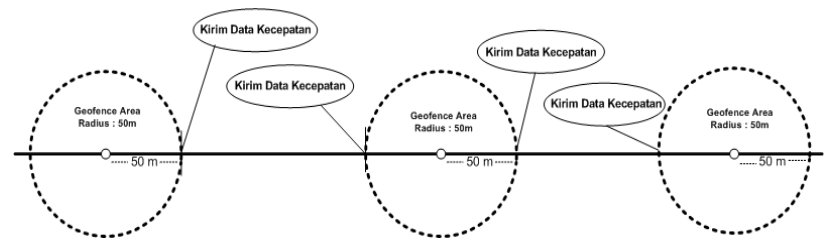

Gambar 2. Pengamatan Kecepatan Dengan Geofence

Geofence ditempatkan pada area ruas jalan pengamatan kondisi lalu lintas, bertujuan untuk memberikan triger pada proses pengambilan data kecepatan kendaraan. Gambar 2 menunjukkan radius yang diatur pada area pengamatan berjarak $50 \mathrm{~m}$ dari titik pengamatan.

\subsection{Arsitektur GPS Pada Smartphone}

Pada era digital seperti saat ini, pendekatan pengumpulan data berdasarkan GPS pada smartphone sangat memungkinkan. Semenjak tahun 2000, produsen ponsel di Amerika Setikat dan Kanada telah menanamkan A-GPS (Assisted Global Possitioning System) Chip pada perangkat mobile untuk 
meningkatkan layanan lokasi berbasis mobile. Secara umum A-GPS pada smartphone bekerja dengan mengunci titik posisi pada suatu lokasi sampai dikunci oleh satelit dengan dibantu jaringan internet pada smartphone seperti hotspot wifi dan BTS transmiter operator telepon (Geovani dan Velerio, 2012).

GPS pada smartphone khususnya android terdiri dari beberapa komponen hardware dan software sehingga mampu menjadi location service dengan tepat. komponen-komponen GPS pada smartphone android :

1. Chip GPS: Berkomunikasi langsung dengan satelit, bertugas sebagai penerima frekuensi langsung pada radio.

2. GPS Driver: Bertugas melakukan komunikasi antara GPS chip dengan Operating System android.

3. GL Engine: adalah sistem yang terpenting dalam pada komponen GPS android. Sistem ini berfungsi untuk mengetahui lokasi yang diambil pada BTS transmitter operator telpon untuk membantu A-GPS mengunci lokasi. Bertugas untuk mengetahui lokasi pada BTS transmiter dan membantu A-GPS dalam mengunci lokasi. Saat mengunci lokasi GL Engine memerlukan informasi tempat, wakti, ketinggian yang diambil dari data satelit. Setelah itu informasi di simpan pada NVRAM.

4. Android Location Services (ALS): Salah satu komponen yang dibutuhkan adalah location manager untuk aplikasi yang menggunakan GL Engine.

5. User Application: Merupakan berbagai macam aplikasi yang menggunakan GPS contohnya : Google map, GPS essential dan lain - lain.

\subsection{Transmisi Data Dengan GPRS}

Teknologi telekomunikasi seluler yang saat ini diterapkan adalah GSM, GPRS, 3G, dan 4G, dan akan diikuti oleh standar 5G. General packet radio service (GPRS) adalah paket fitur komunikasi data pada teknologi GSM, yang memungkinkan untuk mengirimkan data kecepatan tinggi melalui terminal / perangkat ponsel.

Pada saat melakukan trasfer data GPRS dilakukan per kilobyte data transfer. Sangat berbeda dengan transfer data melalui kabel yang dilakukan perhitungan per menit mengakibatkan pengguna tetap membayar walaupun tidak melakukan transfer data (Xiao dan Wang, 2011).

GPRS memiliki berbagai jenis layanan seperti Wireless Application Protocol (WAP), (SMS) Short Message Service dan word wide word (www).

\subsection{Kategori Kepadatan Lalu Lintas}

Informasi keadaan lalu lintas di sampaikan dalam betuk warna garis (polyline) berdasarkan kategori kepadatan lalu lintas seperti yang ditunjukkan pada Tabel 1. Kategori kepadatan diperoleh dengan menggunakan tingkat kejenuhan (Degre of Saturation) jalan arteri di perkotaan dalam keadaan lacar adalah saat kecepatan mencapai $40 \mathrm{~km} / \mathrm{jam}$, keadaan sedang dengan kecepatan 26 sampai $40 \mathrm{~km} / \mathrm{jam}$, keadaan padat dengan kecepatan 17 sampai $27 \mathrm{~km} / \mathrm{jam}$ dan keadaan macet kurang dari 17 km/jam (Warmayana, 2015)

Tabel 1. Kategori Kepadatan Lalu Lintas

\begin{tabular}{ccc}
\hline $\begin{array}{c}\text { Kecepatan } \\
(\mathbf{k m} / \mathbf{j a m})\end{array}$ & $\begin{array}{c}\text { Kategori } \\
\text { Kepadatan }\end{array}$ & Warna Garis (Polyline) \\
\hline$>40$ & Lancar & Hijau \\
$26-40$ & Sedang & Kuning \\
$17-27$ & Padat & Merah \\
$<17$ & Macet & Hitam \\
\hline
\end{tabular}

\section{IMPLEMENTASI}

Implementasi pengamatan kondisi lalu lintas dilakukan pada jalur bus Trans Sarbagita koridor I pada ruas jalan Denpasar Kota - GWK (Garuda Wisnu Kencana) dengan panjang area pengamatan adalah 30 $\mathrm{km}$. Pada bus Trans Sarbagita diletakkan sebuah perangkat smartphone yang sudah terpasang aplikasi berbasis android dengan model geofence seperti pada Gambar 2. Aplikasi berfungsi untuk akuisi data kecepatan dan mengirimkan koordinat pergerakan bus ke server secara periodik. Secara umum dapat ditunjukkan pada Gambar 3.

\subsection{Akuisisi Data Kecepatan Kendaraan}

Kecepatan kendaraan diperoleh melalui perhitungan yang sederhana yaitu jarak tempuh kendaraan dibagi dengan waktu tempuh. Penghitungan kecepatan kendaraan berbasis GPS smartphone menggunakan nilai jarak tempuh dari hasil perpindahan koordinat dalam satuan detik yang kemudian dikonversi menjadi nilai kecepatan yang dinyatakan dalam satuan kecepatan $(\mathrm{km} / \mathrm{jam})$. Gambar 4 menunjukkan ilustrasi pengamatan kondisi lalu lintas berbasis data GPS pada smartphone.

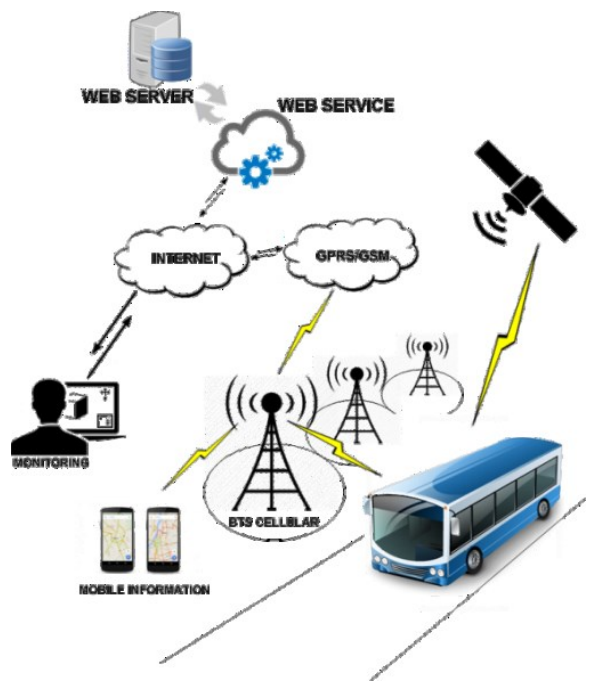

Gambar 3. Ilustrasi Pengamatan Kondisi Lalu Lintas

Pada gambar 4 menunjukkan, jarak perpindahan koordinat kendaraan di ambil per lima detik. Untuk mendapatkan kecepatan perpindahan koordinat 
perdetiknya dilakukan dengan membagi lima jarak perpindahan koordinat tersebut. Selanjutnya kecepatan perpindahan koordinat dalam satuan detik di konversi sehingga data kecepatan kendaraan dicatat pada server dalam satuan $\mathrm{km} / \mathrm{jam}$ seperti ditunjukkan pada tabel 2 .

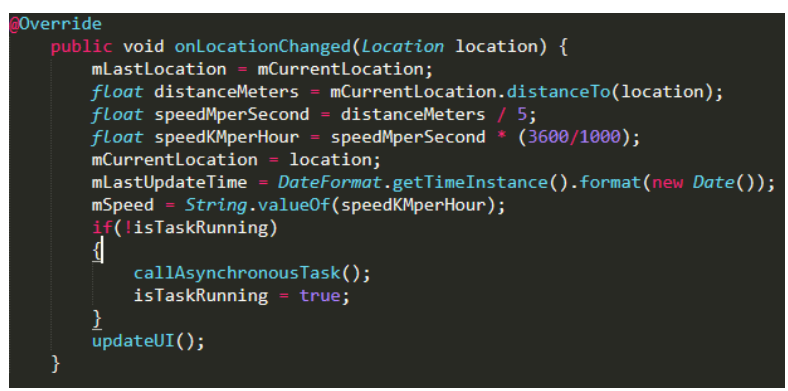

Gambar 4. Blok Kode Akuisisi Kecepatan Kendaraan

\subsection{Pengiriman Data Kecepatan Kendaraan}

Setelah akuisisi data kecepatan kendaraan berhasil, selanjutnya data kecepatan dan koordinat dikirim ke server melalui jaringan GPRS pada smartphone seperti yang ditunjukkan pada Gambar 5.

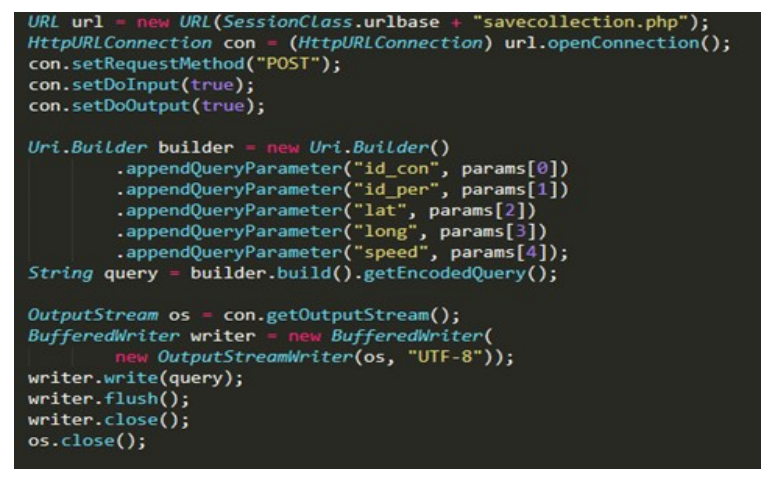

Gambar 5. Blok Kode Untuk Pengiriman Data

\subsection{Proses Informasi Kondisi Lalu Lintas}

Data kecepatan kendaraan di simpan pada database server selanjutnya diproses sebagai informasi keadaan lalu lintas yang di sampaikan dalam bentuk garis (polyline) berwarna seperti yang ditunjukkan pada Gambar 6. Warna garis (polyline) menunjukkan kondisi lalu lintas berdasarkan data kecepatan kendaraan, untuk kecepatan kendaraan dibawah $17 \mathrm{~km} / \mathrm{jam}$ maka warna garis polyline berwana hitam, kecepatan kendaraan 17 sampai $26 \mathrm{~km} / \mathrm{jam}$ garis polyline berwarna merah, kecepatan kendaraan 27 sampai dengan $40 \mathrm{~km} / \mathrm{jam}$ berwarna kuning dan jika kecepatan kendaraan diatas 40 $\mathrm{km} / \mathrm{jam}$ maka garis polyline berwarna hijau. Hal ini akan mempermudah dalam melihat kondisi lalu lintas.

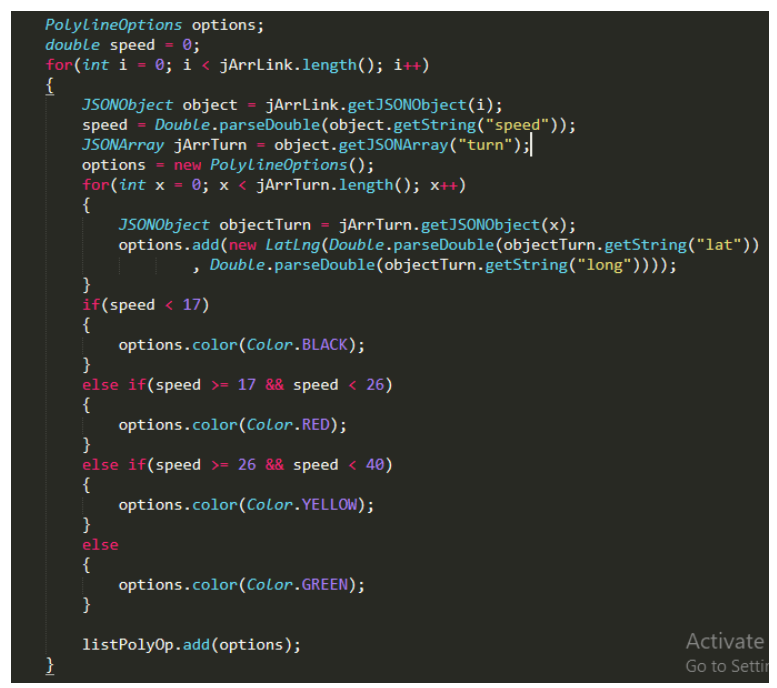

Gambar 6. Blok Kode Menampilkan Kondisi Lalu Lintas

\section{HASIL DAN PEMBAHASAN}

\subsection{Antarmuka Aplikasi Akuisisi Data}

Antarmuka pada aplikasi berbasis Android yang diletakkan pada bus digunakan untuk memastikan bahwa aplikasi sudah berjalan dengan baik dan sudah mampu mendeteksi koordinat dan kecepatan kendaraan melalui GPS yang ada pada perangkat smartphone. Antarmuka aplikasi ditujukan pada Gambar 7 sudah mampu menampilkan data kecepatan kendaraan beserta koordinat.

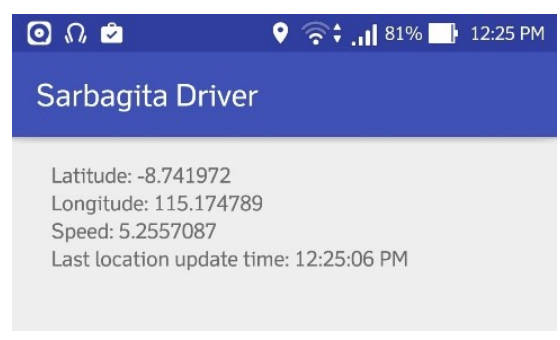

Gambar 7 Antarmuka Aplikasi Akuisisi Data Kecepatan Kendaraan

\subsection{Data Kecepatan Kendaraan}

Setelah data kecepatan dan koordinat berhasil di akuisisi selanjutnya data disimpan pada database sever yang akan dijadikan dasar untuk informasi keadaan lalu lintas. Tabel 2 menunjukkan data kecepatan kendaraan yang sudah tersimpan di database server pada tanggal $03 / 02 / 2019$. Rata-rata kecepatan kendaraan pada ruas jalan pengambilan data dalam kategori sedang dengan kecepatan $26 \mathrm{~km} / \mathrm{jam}$ sampai $34 \mathrm{~km} / \mathrm{jam}$, namun pada persimpangan jalan tercatat kecepatan kendaraan padat dengan rata-rata kecepatan $17 \mathrm{~km} / \mathrm{jam}$ sampai 25 $\mathrm{km} / \mathrm{jam}$. 
Tabel 2. Data Kecepatan Kendaraan

\begin{tabular}{ccccc}
\hline No & $\begin{array}{c}\text { ID } \\
\text { Link }\end{array}$ & Kecepatan & $\begin{array}{c}\text { Transisi } \\
\text { Link }\end{array}$ & Tanggal \\
\hline 1 & 3 & 31,9 & 1 & $03 / 02 / 2019$ \\
\hline 2 & 3 & 26,1 & 2 & $03 / 02 / 2019$ \\
\hline 3 & 4 & 32,5 & 1 & $03 / 02 / 2019$ \\
\hline 4 & 4 & 34,2 & 2 & $03 / 02 / 2019$ \\
\hline-- & -- & ---------- \\
\hline 91 & 49 & 19,4 & -- & $----\cdot-\cdot 2019$ \\
\hline 92 & 49 & 28,2 & 1 & $03 / 02 / 2019$ \\
\hline 93 & 50 & 26,05 & 1 & $03 / 02 / 201 / 2019$ \\
\hline 94 & 50 & 29,3 & 2 & $03 / 02 / 2019$ \\
\hline
\end{tabular}

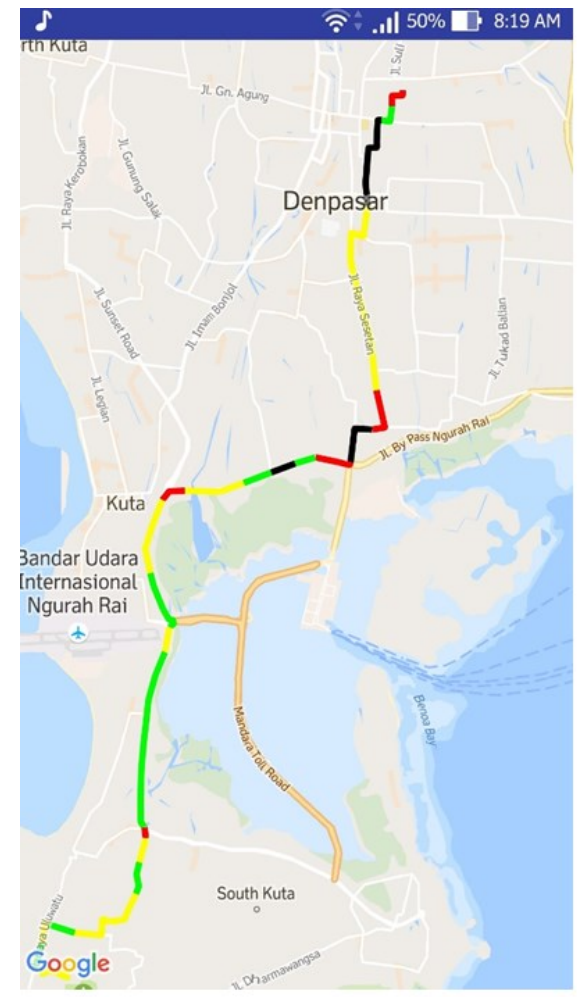

Gambar 8. Informasi Kondisi Lalu Lintas

\subsection{Informasi Lalu Lintas}

Informasi lalu lintas diperoses berdasarkan kecepatan rata-rata kendaraan dengan mengambil nilai rata-rata kecepatan pada perjalan kendaraan yang terakhir melintasi ruas jalan. Informasi lalu lintas dikategorikan berdasarkan kondisi yaitu macet (warna hitam), padat (warna merah), sedang (warna kuning) dan lancar (warna hijau) seperti refrensi pada Tabel 1. Informasi lalu lintas ditampilkan pada peta grafis GIS.

Gambar 8 menunjukkan informasi kondisi lalu lintas berdasarkan data kecepatan kendaraan dengan garis warna (polyline) pada ruas jalan pengamatan di kota Denpasar. Garis warna merah menunjukkan kecepatan rata-rata kendaraan $17 \mathrm{~km} / \mathrm{jam}$ sampai 26 $\mathrm{km} / \mathrm{jam}$ dengan kategori lalu lintas padat, garis warna hitam menunjukkan kecepatan rata-rata kendaraan di bawah $17 \mathrm{~km} /$ jam dengan kategori lalu lintas macet hal ini dapat terlihat pada ruas persimpangan jalan, garis warna kuning menunjukkan kecepatan rata-rata kendaraan $26 \mathrm{~km} / \mathrm{jam}$ sampai $40 \mathrm{~km} / \mathrm{jam}$ dengan kategori lalu lintas sedang dan garis warna hijau menunjukkan kecepatan kendaraan diatas $40 \mathrm{~km} / \mathrm{jam}$ dengan kategori lalu lintas lancar hal ini dapat terlihat pada ruas jalan bypass dengan gangguan samping yang minimal.

\section{KESIMPULAN}

Implementasi model pengamatan kondisi lalu lintas pada ruas jalan koridor I Denpasar - GWK telah berjalan dengan lancar. Perangkat smartphone yang di letakkan pada kendaraan (bus Trans Sarbagita) sudah mampu mendapatkan koordinat dan kecepatan kendaraan dan berhasil melakukan pengiriman data dengan tepat ke server. Pada sisi server sudah berhasil mencatat setiap pergerakan kendaraan beserta kecepatannya sehingga informasi konsisi lalu lintas dapat di tampilkan. Informasi kondisi lalu lintas di tampilkan berbasis data spasial (GIS) berdasarkan data kecepatan yang dikategorikan dengan warna garis (polyline). Pada kondisi lalu lintas padat seperti di persimpangan informasi kondisi lalu lintas di tampilkan dengan garis warna hitam dengan kecepatan kedaraan di bawah $17 \mathrm{~km} / \mathrm{jam}$, pada kondisi lancar seperti di jalan bebas gangguan samping atau jalan bypass informasi lalu lintas di tampilkan dengan warna garis hijau dengan kecepatan rata-rata diatas $40 \mathrm{~km} / \mathrm{jam}$.

\section{DAFTAR PUSTAKA}

AVINAS, H., Dkk., 2016. Map Land Surveying System. Imperial Journal of Interdisciplinary Research (IJIR). 2 (5).

DEKRENERIS. 2010. Integrating GIS, GPS and GSM Technologies for the Effective Management of Ambulances. Computer Environment and Urban System. 25 (3). 267-78.

GIOVANI, P., dan VALERIO MARIO, S. 2012. A GPS Based Architecture to Control Bus Trough an IOS Application. Kore University of Enna, Italy.

http://isad12s.guap.ru/files/publications/if2011/ pau.pdf.

KUHN, J., dan VOGT, P. 2013. Application and Examples of Experiments with Mobile Phone and Smartphone in Physics Lessons. Frontier in Sensor (FS). 1 (4). 67-73.

MUSTAPHA, A. M., Dkk, 2011. Implementing Bus Identification and Monitoring System. International Conference on Electrical, Control and Computer Engineering (InECCE).

SETIAWAN, G.H., WIDYANTARA, I.M.O., dan SUDARMA, M. 2016 Vehicle Speed Observation Models Based on the Data on the Smartphone GPS. Journal Computer Technology and Application. (7). 300-307.

SETYAWAN, G. E., Dkk., 2019 Sistem Deteksi Jumlah, Jenis dan Kecepatan Kendaraan Menggunakan Analisa Blob Berbasis Raspberry Pi. Jurnal Teknologi Informasi dan Ilmu Komputer (JTIIK). 6(2). 211-218 
672 Jurnal Teknologi Informasi dan Ilmu Komputer (JTIIK), Vol. 7, No. 4, Agustus 2020, hlm. 667-672

WARMAYANA, I.G.A.K., 2015. Sistem Informasi Trafik Lalu Lintas Cerdas di Bali. Tesis. Progran Pascasarjana Universitas Udayana.

WIDYANTARA, I.M.O., dan SASTRA, N.P., 2015. Internet of Things for Intelligent Traffic Monitoring System: A Case Study in Denpasar. IJCTT. 30 (3). 169-73

XIAO, L., dan WANG, Z. 2011. Internet of Things: A New Application for Intelligent Traffic Monitoring System. Journal of Network. 6 (6). 887-94. 